\title{
The Role of Regret in Medical Decision-making
}

\author{
Paddy McQueen ${ }^{1}$
}

Accepted: 20 October 2017 / Published online: 4 November 2017

(C) The Author(s) 2017. This article is an open access publication

\begin{abstract}
In this paper, I explore the role that regret does and should play in medical decision-making. Specifically, I consider whether the possibility of a patient experiencing post-treatment regret is a good reason for a clinician to counsel against that treatment or to withhold it. Currently, the belief that a patient may experience post-treatment regret is sometimes taken as a sufficiently strong reason to withhold it, even when the patient makes an explicit, informed request. Relatedly, medical researchers and practitioners often understand a patient's post-treatment regret to be a significant problem, one that reveals a mistake or flaw in the decision-making process. Contrary to these views, I argue that the possibility of post-treatment regret is not necessarily a good reason for withholding the treatment. This claim is justified by appealing to respect for patient autonomy. Furthermore, there are occasions when the very reference to post-treatment regret during medical decision-making is inappropriate. This, I suggest, is the case when the decision concerns a "personally transformative treatment". This is a treatment that alters a person's identity. Because the treatment is transformative, neither clinicians nor the patient him/herself can ascertain whether post-treatment regret will occur. Consequently, I suggest, what matters in determining whether to offer a personally transformative treatment is whether the patient has sufficiently good reasons for wanting the treatment at the time the decision is made. What does not matter is how the patient may subsequently be changed by undergoing the treatment.
\end{abstract}

Keywords Medical decision-making · Regret · Sex/gender reassignment surgery · Transformative experience $\cdot$ Voluntary sterilisation

Paddy McQueen

paddymcqueen@gmail.com

1 School of HAPP, Queen's University Belfast, 25 University Square, Belfast, Northern Ireland BT7 $1 \mathrm{NN}$ 


\section{Introduction}

In this paper, I explore the role that regret does and should play in medical decision-making. ${ }^{1}$ Specifically, I consider whether the possibility of a patient experiencing post-treatment regret is a good reason for a clinician to counsel against that treatment or to withhold it. This is an important issue to address given the significant impact that medical treatment can have upon a person's physical and psychological health. Determining when a treatment is appropriate understood here as a process of weighing the reasons for and against it - is thus a matter of vital concern to both patients and doctors. Currently, the belief that a patient may experience post-treatment regret is sometimes taken as a sufficiently strong reason to withhold it, even when the patient makes an explicit, informed request (Brockwell 2015). Relatedly, medical researchers and practitioners often understand a patient's post-treatment regret to be a significant problem, one that reveals a mistake or flaw in the decision-making process.

Contrary to the above views, I argue that the possibility of post-treatment regret is not necessarily a good reason for withholding the treatment. This claim is justified by appealing to respect for patient autonomy. Furthermore, there are occasions when the very reference to posttreatment regret during medical decision-making is inappropriate. This, I suggest, is the case when the decision concerns a "personally transformative treatment". This is a treatment that alters a person's identity (e.g. their preferences, feelings, desires, values, life-plans and/or relationships). Because the treatment is transformative, neither clinicians nor the patient him/ herself can ascertain whether post-treatment regret will occur. Consequently, I suggest, what matters in determining whether to offer a personally transformative treatment is whether the patient has sufficiently good reasons for wanting the treatment at the time the decision is made. What does not matter is how the patient may subsequently be changed by undergoing the treatment.

\section{What is Regret?}

Regret is a complex, multivalent concept (Landman 1993). One can use the term as a somewhat empty, ritualised expression for having to perform an action that will cause someone sadness or suffering, e.g. "We regret to inform you that we are unable to accept your paper for publication in this journal". One can also use the term to express sympathy, sorrow or grief, e.g. "It was with much regret that I learned of your recent misfortune". Furthermore, we may refer to human or natural events as "deeply regrettable". Finally, "agent regret" (Rorty 1980) refers to a person's attitude ${ }^{2}$ toward their decisions that they wish they had not made. Typically, this will be because the consequences of the decision were worse than they had expected them to be (Gilovich and Medvec 1995; Zeelenberg et al. 2000). Agent regret is often experienced

\footnotetext{
${ }^{1}$ By "medical decision-making" I refer to the process by which a course of treatment is determined to be appropriate for a patient. I assume that the decision-making process will be guided by (a) concern for the patient's (best) interests; (b) respect for the patient's autonomy; and (c) adherence to generally accepted moral principles. This account is idealised compared to how decisions are often made in hospitals and doctors' surgeries, where pressures of time, financial constraints, and the lack of equipment, information and suitably-skilled staff can influence what treatments are offered.

${ }^{2}$ This attitude incorporates both feelings and judgements: I feel regret and simultaneously judge that something is regrettable. Thus, Landman $(1993,36)$ describes regret as 'an experience of felt-reason or reasoned-emotion', whilst Zeelenberg and Pieters $(2007,6)$ use the term 'cognitive emotion'.
} 
as a form of self-reproach and is taken to reveal that one's decision-making was flawed (Bourgeois-Gironde 2010). In what follows, it is this final form of regret that I discuss and to which I refer when using the word.

Regret is a negative emotion: it is unpleasant to experience regret and we often strive to avoid it (Janis and Mann 1977; Zeelenberg and Pieters 2007). Typically, this involves subjecting important decisions to extensive reflection before acting to ensure the best option is taken and the optimal outcome is achieved. Anticipated regret thus plays a role in people's decision-making processes (Zeelenberg 1999; Zeelenberg et al. 1996). This includes decisionmaking about medical treatment (Speck et al. 2016). Because the experience of regret is unpleasant, and because we tend to assume that it indicates a flawed decision, the belief that we will regret doing something is taken as a strong reason against that course of action. This suggests that we can be justified in endeavouring to prevent both ourselves and others from experiencing regret. However, as I will argue below, sometimes we should take decisions that we might come to regret. Furthermore, not all regrets can be avoided simply by making more better decisions. Thus, some regrets do not demonstrate a flaw in the decision-making process. This is because some regrets are unforeseeable and uncontrollable from the perspective of the agent at the time that she is deliberating about what to. These claims will be explained and defended once the current understanding of regret within medical practice and research has been examined.

\section{Clinical Perspectives on Patient-regret}

The issue of regret has received relatively little attention from philosophers. ${ }^{3}$ Within medical ethics and health care, post-treatment regret has been documented in relation to, for example, cancer treatments (Christie et al. 2015; Fernandes-Taylor and Bloom 2010), abortion (Fergusson et al. 2009; Major 2000), gender confirmation treatment (Olsson and Möller 2006; Smith et al. 2005) and voluntary sterilisation (Curtis et al. 2006; Hillis et al. 1999). However, its normative status in and implications for medical decision-making are rarely assessed. Owing to the limitations of space, I will discuss regret in relation to gender confirmation treatment (GCT) and voluntary sterilisation (VS). In focusing on them, I do not mean to efface the many differences between them. For example, GCT is a complex, multistage and expensive process, whereas sterilisation is a quick, cheap, one-off procedure. Poststerilisation regret will thus target a single, isolated decision, whereas post-GCT regret can target either the cumulative effect of a series of decisions or a part of that process. What unites them, for the purposes of this paper, is that many clinicians and researchers have expressed concern that patients will regret undergoing GCT or being sterilised. ${ }^{4}$ I will refer to this regret as "patient-regret". It is often assumed that patient-regret (a) is a strong reason against offering

\footnotetext{
${ }^{3}$ Notable exceptions include Rorty (1980), Williams (1981), Bittner (1992); Bagnoli (2000) and Wallace (2013).

${ }^{4}$ Several factors may explain clinicians' worries about patient-regret following GCT or VS. Both are likely to have a significant impact upon a person's well-being. Both are nominally irreversible - reversing them is difficult, expensive and success rates are variable depending on what is being reversed - and concern features of a person - gender and parenthood - that, at least within contemporary societies, are fundamental to who one is and how one experiences the world. This renders decisions to transition and to forego having children very significant ones, and hence ones that it is natural to want to get right. It may also render a person's regret about transitioning or being sterilised more painful.
} 
these treatments; and (b) reveals a problem in the decision-making process through which the treatment was identified as appropriate.

Before proceeding, a few clarificatory remarks about GCT may be helpful. I use the term to refer to the process of physically changing one's sex/gender, ${ }^{5}$ which is achieved through hormone treatment and surgery. The alteration of a person's sex/gender is also referred to as sex or gender reassignment surgery (SRS / GRS). I will treat these terms as synonymous as they refer to the same group of medical treatments and procedures. For trans men, these include taking testosterone, bilateral mastectomy, hysterectomy, phalloplasty, scrotoplasty and penile implant. For trans women, these include taking oestrogen, facial feminisation surgery, orchidectomy, vaginoplasty, vulvoplasty, clitoroplasty and breast implants.

Many trans individuals undergo only some of these procedures, either through choice, medical limitations or financial constraints (Davy 2011). There is thus variety in how people transition and what their desired gender identity is. Furthermore, trans individuals are demographically diverse. Although more cis men than cis women are recorded as trans, the difference in population size is not vast - although numbers vary from study to study and country to country - and is diminishing (Meier and Labuski 2013; Reed et al. 2011; Whittle et al. 2008). ${ }^{6}$ People of many different ages transition and they may identify themselves as trans when very young or much later in life (Davy 2011; Flores et al. 2016; Nealy 2017). Finally, trans individuals are situated across the economic spectrum, although they tend to be towards the poorer end of it (Whittle et al. 2008).

Despite this diversity, much of the medical research focuses exclusively on male-to-female transsexuals. Nevertheless, what is important about this research is that it treats the possibility of a person coming to regret their decision to transition as a major problem. For example, Olsson and Möller $(2006,501)$ argue that 'Persistent regret after sex reassignment surgery... must be considered, along with suicide, as the worst possible outcome of SRS'. As a result, 'Every regret case represents a major clinical and ethical problem' (502). These are strong claims: regret is comparable to suicide in terms of negative outcomes following GCT and every regret case must be considered a major clinical and ethical problem. Expressing similar concerns, Landén et al. $(1998,287)$ state that 'Every effort must be made to avoid individuals who ask for a reversal of sex reassignment'; Smith et al. $(2005,90)$ declare that 'it is imperative to try and prevent post-operative regret'; and Smith et al. $(2001,472)$ highlight that 'one of the main objections of professionals against a start of the sex reassignment procedure before 18 years [of age] is the risk of postoperative regret'.

The possibility of post-treatment regret is sometimes treated as a strong reason, even a sufficient and overriding one, for withholding GCT (cf. Batty 2004; Duke 2014). Jeffreys $(2008,2014)$ draws on occurrences of post-transition regret to support her argument that GCT should be banned. Similarly, the website "sexchangeregret.com" is dedicated to documenting experiences of regret following GCT. The website's author, Walt Heyer, argues that GCT is an inappropriate response to / solution for gender dysphoria. Although he stops short of calling for it to be banned, he stresses that it can cause 'irreversible damage' and urges individuals

\footnotetext{
${ }^{5}$ Theorists have critiqued the tenability of a clear distinction between a person's sex and their gender (e.g. Fausto-Sterling 2000). I use the term "sex/gender" to acknowledge this without being able to discuss it further here.

${ }^{6}$ The existing data are, however, problematic (Meier and Labuski 2013). First, many individuals do not openly declare themselves to be trans. Second, a potentially large number of trans individuals do not choose medical treatment and thus are not recorded in many statistics. Third, the term "trans" covers a wide array of gender identities and research may include only a certain portion of them.
} 
who are considering GCT to proceed with 'extreme caution'. There is a strong implication underpinning the content of the website that one will likely come to regret transitioning. Heyer and Jeffreys take post-treatment regret to indicate a problem with GCT itself and to be a strong reason for denying individuals' requests for it.

Olsson and Möller (2006, 502-3) state that their case report 'will hopefully contribute to a growing body of knowledge that in the future will reduce the number of bad choices for SRS and also the number of regret cases'. Their view implies that post-treatment regret is linked to / caused by poor decision-making. Similarly, Djordjevic et al. (2016) equate post-GCT regret with misdiagnosis. If the decision-making process had been improved, the argument suggests, then regret would have been avoided (perhaps psychotherapy or some other means of working through the patient's feelings of gender dysphoria, would have been more effective / appropriate). I think this line of thinking is problematic, as I will explain below.

Worries that a patient will experience post-treatment regret are also voiced in relation to sterilisation requests, especially when the patient is a childfree woman under the age of 30 (Lawrence et al. 2011). ${ }^{7}$ The major concern is that such women will later want to have children, which will result in significant regret. This leads to many requests for sterilisation made by young, childfree women being denied (Campbell 1999; Gillespie 2000). Indeed, Richie $(2013,38)$ reports that women's accounts of denied sterilisation requests are 'ubiquitous'. ${ }^{8}$ Thus, when discussing sterilisation requests, I refer primarily to childfree women under the age of 30. I will examine whether the possibility that these women will regret choosing to be sterilised is a good reason to deny their requests for it. However, my argument will apply also to postpartum women who request sterilisation, should concerns be raised that they too may regret their decision.

Much of the research into women's experiences of sterilisation is focused on factors associated with post-sterilisation regret (Curtis et al. 2006; Hillis et al. 1999). The implicit assumption underlying this research is that patient-regret is undesirable and should be prevented, which can be achieved by improving the decision-making process. Whilst clinicians' concerns about patient-regret may well be commendable, given the unpleasantness of regret, it is important to consider whether a patient's future regret is something that clinicians (a) should prevent; and (b) can prevent. Because the latter is a more complex issue than the former, I shall deal with the former first.

\section{Should a Patient's Regret be Prevented?}

Let us assume that the experience of regret is detrimental to one's wellbeing (Jokisaari 2003): one's life goes better, other things being equal, if one has fewer regrets. Given this assumption, it seems reasonable for clinicians to strive to reduce the likelihood of patient-regret. Doing so, it might be argued, will improve patient well-being and indicate that the treatment was appropriate. It would thus be consistent with the principle of beneficence, which is a central component of medical ethics (Beauchamp and Childress 2013, 203ff). However, this must be considered in relation to another key principle of medical ethics: respect for patient autonomy (214ff).

\footnotetext{
${ }^{7}$ The demography of women who request sterilisation is diverse (Hillis et al. 1999; Zite and Borrero 2011). They come from a wide range of racial, ethnic and socio-economic groups, may be single or with a partner, and may have no, one or several children.

${ }^{8}$ Notably, it seems to be much easier for a man to be sterilised than a woman (Richie 2013).
} 
Discussion of autonomy can be difficult, given the numerous ways it is understood (Christman 1989; Mackenzie and Stoljar 2000). ${ }^{9}$ Within medical ethics, autonomy is often equated with informed consent about one's medical care, principally the right to refuse treatment (which was historically necessary, given the strong paternalism that pervaded health care). However, I will understand it in a deeper sense, as relating to how a person organises their life in respect to their central values, desires and projects. To be autonomous is to be able to lead a life, which involves reflection on one's goals and projects. Thus, to respect someone's autonomy is to recognise them as capable of shaping their life and the kind of person they want to be. ${ }^{10}$

On this richer account, respect for patient autonomy is not just a matter of consenting to treatment, it also includes a presumption that clinicians should consider a patient's expressed desires, values, feelings and plans when considering what treatment is appropriate. This is central to patient-centred care (Epstein and Street 2011). Clinicians are not legally required to agree to a patient's request for treatment - although they are legally required to accept a patient's refusal of treatment - but the patient may legitimately expect them to agree to it unless there are sufficiently strong reasons against the treatment (and I am interested in whether post-treatment regret constitutes such a reason).

This applies not only to life-saving or life-preserving treatment, but also to life-enhancing treatment. For example, a patient may request an intrauterine device (IUD) as their preferred form of contraception, with the expectation that their doctor will agree to this request. Alternatively, a doctor may prescribe diazepam to a patient with severe aviophobia. In both cases, the treatment is not physiologically necessary - the patient's physical health will not worsen if the request is denied ${ }^{11}$ - but rather is aimed at improving the patient's quality of life. It is likely that there is a blurred line between treatments and procedures that fall within the remit of medical health care and those that are considered "cosmetic". However, I assume it is reasonable to include GCT and VS as a part of medical health care. For GCT, this is because of the psychological distress / existential suffering associated with gender dysphoria. For VS, this is because of the importance that reproductive control has for a person's well-being and sense of dignity, the fact that some people are unable to utilise other forms of contraception, and the significant impact that unplanned pregnancy and parenthood can have on a person's body and life. $^{12}$

Consider, then, the type of sterilisation request that many clinicians are reluctant to agree to. ${ }^{13}$ A 27 -year-old woman is certain that she wants to live a childfree life. She thinks that parenthood is incompatible with many of her central values, feelings and projects. She has an adverse reaction to the pill and cannot use an IUD owing to a copper allergy. However, even if

\footnotetext{
${ }^{9}$ My thanks to an anonymous reviewer for pushing me to clarify my understanding of autonomy and its implications for my argument.

${ }^{10}$ This is not to impute to people the ability for radical self-creation ex nihilo. We all find ourselves with a complex identity that is not of our choosing. Nevertheless, we retain the ability to make significant life decisions about who we want to be that reflect core values and feelings, even if these values and feelings are not of our choosing.

${ }^{11}$ An exception would be if a sexually-active woman has a health condition that would threaten her physical health, were she to become pregnant. Here, the IUD might be deemed to be life-saving or life-preserving.

${ }^{12}$ Given that suicide rates among the trans population are reported between 30 and 40\% (Haas et al. 2014; Whittle et al. 2008, and given that various medical conditions can severely impact the health of a pregnant woman and her foetus, then both perhaps GCT and VS can, in some cases at least, be classified as life-saving.

13 The description is based on the real-life example of Holly Brockwell (Brockwell 2015).
} 
she could use an IUD, she is adamant that sterilisation is her preferred method of contraception. She is aware that it is a permanent, irreversible procedure (she sees this as a positive aspect of sterilisation). She is also aware that she might later change her mind and want to become pregnant, although she is adamant that she has no reason to think it will happen. This awareness does not undermine or erode her desire for sterilisation. She insists that she is happy to live with the consequences of their decision, even if she does change her mind. She is happy to live with her regret.

Respect for the patient autonomy entails that the doctor ought to agree to the request. (This argument is, of course, intended to apply to other medical treatments, such as GCT, that give rise to worries about patient-regret). The desire not to have children is persistent, has been subjected to extensive self-reflection, and is consistent with the patient's values and long-term plans. It remains possible that she may change as a person in a such way that she does want to have children. We cannot guarantee that our identities will remain unchanged throughout our lives. Nevertheless, her request for sterilisation is an autonomous one: it is made following extensive reflection on her deeply-held values, feelings and projects. When confronted with such a request, clinicians should not shield us from future regret. As Richie $(2013,39)$ argues, 'regret is the competent woman's burden, not the doctor's'. Similarly, Denbow $(2015,70)$ claims that being autonomous 'entails living with the consequences of decisions instead of being relentlessly protected from potential adverse outcomes'. Part of respecting a person's autonomy is allowing them to make decisions that could later be regretted, so long as the decision can be justified at the time it is made.

We may still hold that clinicians should make patients aware of the possibility of posttreatment regret and factors that might induce or exacerbate it, such as the irreversibility or negative side-effects of the treatment. This would help patients to make more informed decisions. However, the possibility of regret should not be taken as an overriding reason to withhold a treatment, so long as the request is made in an autonomous, sufficiently-informed manner. It is notable that this perspective on regret and autonomy seems to be adopted in other areas of medical decision-making. For example, the possibility of regret is not raised when a patient requests IVF treatment or an organ removal for donation, even though both can have a significant impact upon one's life and well-being. ${ }^{14}$ Nevertheless, people have expressed regrets about choosing to have IVF treatment (BBC 2013; Connell 2013; Daniluk 2001) and there is a growing body of literature documenting people's regrets about having children (Donath 2015; Marsh 2017). This suggests a questionable asymmetry between the role that regret plays in decision-making about sterilisation compared to, say, IVF (Mertes 2016).

The appeal to patient autonomy will leave occasions when the patient's request for treatment should be denied. For example, a young, childfree woman may request sterilisation but still express her desire to give birth to children later in their life and has planned her future accordingly (perhaps because she does not realise it is irreversible). The request cannot be justified, given the patient's identity, and so it is appropriate for the clinician to deny it. Because the patient lacks good reasons for wanting the treatment, we are right to expect them to later regret their decision and to act to prevent this regret (just as someone who goes against their better judgement and, in a moment of rashness, buys a car that is clearly in need of repair

\footnotetext{
${ }^{14}$ In the UK, the eligibility criteria for IVF treatment contain no reference to patient-regret, such as the expectation that the individual will not regret their decision. http://www.nhs. uk/Conditions/IVF/Pages/Availability.aspx and http://www.nice.org.uk/guidance/cg 156 /chapter/Recommendations\#access-criteria-for-ivf.
} 
or unsuitable for their needs will likely come to regret doing so). However, if a woman's identity does count strongly in favour of sterilisation - she is sure she does not want to have children; her values and future plans are incompatible with parenthood; she is willing to accept the consequences of her decision - then refusing her request by appealing to future regret would be unjustifiable. This is because it fails to respect her autonomy.

\section{Can a Patient's Regret be Prevented?}

In the previous section, I claimed that a clinician's desire to prevent patient-regret can be outweighed by respect for patient autonomy. This still treats prospective regret as relevant to the medical decision-making process: preventing regret plays a role, just not a decisive one, in determining whether a treatment should be offered to a patient. However, it can be argued that, for some treatments, regret should play no role in deciding whether a treatment is appropriate. This, I suggest, is the case when the decision is about a "personally transformative treatment" (PTT).

A PTT is a treatment that changes a person's identity (e.g. their preferences, values, beliefs, feelings or projects). Furthermore, what it is like to experience these changes first-personally what it will be like for me to experience them - cannot be known beforehand and so one will only know how one feels about the changes when one has undergone them. PTTs represent what Paul (2014) refers to as transformative experiences. A transformative experience, she writes, is one that 'can change your point of view, and by extension, your personal preferences, and perhaps even the kind of person that you are or at least take yourself to be' (16). Importantly, it 'teaches you something new, something that you could not have known before the experience, while also changing you as a person' (17).

In practice, it may be difficult to decide whether a treatment will be personally transformative. Nonetheless, there seem to be some reasonably clear-cut cases. Taking antibiotics or having a tooth removed will not be personally transformative. Conversely, deep brain stimulation, having one's sight or hearing restored, chemotherapy, organ transplantation (especially facial allograft transplantation), having one's legs amputated, successful IVF, and antidepressants such as Prozac are likely to be personally transformative (Glannon 2009; Maguire and McGee 1999; Matthews 2011; Svenaeus 2012; Swindell 2007). ${ }^{15}$ It is likely that undergoing these treatments will alter an important element of one's self and represent an experience that is epistemologically novel. How one experiences and feels about one's life and the world will be changed by the treatment: one will develop new feelings, preferences, values, projects, plans sand/or interpersonal relationships. Furthermore, one's evaluative framework the lens through which one assesses one's life and the decisions that one has made - will itself be reworked by experiencing the treatment. This is because one's evaluative framework is constituted by one's identity. Crucially, this affects whether one will regret undergoing the treatment, for the assessment and experience of regret is determined by one's current evaluative framework, and this framework is constitutively altered by a PTT.

Does GCT constitute a PTT? One reason for thinking it does not is that the person undergoing GCT will almost certainly have been living as their preferred gender for some

\footnotetext{
${ }^{15}$ As a reviewer oberved, it is unlikely that VS is a PTT. It is a quick, one-off procedure that will not provide an epistemically novel experience, identity-changing effect. Thus, the argument in this section will apply to GCT and not to VS.
} 
time. ${ }^{16}$ Thus, after undergoing GCT, the person will be the same gender as they have previously identified with and lived as. ${ }^{17}$ However, there are several reasons in favour of deeming it to be a PTT. First, taking hormones will have a significant effect on one's emotional states, body, behaviour and social interactions (Rubin 2003; Davy 2011). What it will be like first-personally to experience these changes, and how one will feel about them, cannot be known prior to taking the hormones. Second, the actual experience of having, say, vaginoplasty or phalloplasty can be phenomenologically significant, changing one's body schema and bodily activities (e.g. how one experiences sexual pleasure, both with oneself and other people). Third, there is an important difference between using clothing and behaviour to inhabit one's desired gender identity and physically altering one's body. Fourth, one's identity and sense of self are heavily shaped by one's social relationships and experiences. These, in turn, will be strongly affected by the transition treatments one has undergone. In sum, 'Changing one's gender... will radically change one's life' (McKinnon 2015, 422). Consequently, 'The decision to transition... is also a paradigmatic transformative decision' (423).

To appreciate the challenge that PTTs pose for medical decision-making, consider what I take to a plausible, albeit idealised, account of how GCT is deemed to be appropriate for a patient. (If one does not think that GCT is personally transformative, then one can run the example with a treatment that is considered to be so). A gender dysphoric individual requests GCT. In deciding whether to agree to the request, clinicians will try to determine what the patient's feelings, preferences, values and plans are. This will include answering questions such as: does the patient have an enduring, stable desire to live in an alternative sex/gender? Do their preferences for the life that they want to lead fit with such transitioning? Do they understand what the procedures involve? In sum, does the patient's preference-set render GCT the most appropriate treatment? In addition, they will want to know how the treatment will affect the patient's life. This will involve establishing how the patient will feel about the treatment after they have transitioned: they will want to be sure that the patient will not regret their decision.

The difficulty GCT (or alternative PTT) poses is that it is personally transformative. Thus, what it will be like for the person to undergo GCT - to take hormones, to inhabit their altered body, to live in society as their new sex/gender - is not something that they can know prior to transitioning. Thus, they cannot how they will feel about undergoing GCT (i.e. what their postGCT life will be like) until they have completed it; they cannot not know beforehand how their sense of self and their evaluative framework will be altered by GCT. As McKinnon (2015, 422) observes, 'in almost all cases, one's post-transition preferences will have shifted over time: it's impossible to predict what gender presentation preferences one will have post transition, and how those choices will feel like, and how they will affect others' interactions with oneself'.

Consequently, neither the patient nor doctor can know whether the patient will regret their decision to undergo GCT, until the decision is made. This means we cannot be guaranteed to prevent regret from occurring because we cannot know the person will be changed by the treatment (which includes what it is like to experience the change and how they feel about it). Thus, when confronted with a PTT, I suggest that the possibility of patient-regret should be deemed irrelevant to the decision-making process. What matters is that (a) the patient is

\footnotetext{
${ }^{16}$ It is common requirement for surgery that trans individuals spend a minimum of a year living in their preferred gender role (NHS Choices 2016).

${ }^{17} \mathrm{I}$ am grateful to an anonymous reviewer for this point.
} 
sufficiently informed about the treatment; (b) the patient has sufficiently good reasons, at the time of asking, for wanting it; and (c) these reasons are consistent with the patient's central values, preferences, plans and the like. What does not matter whether patient-regret will occur. This cannot be known prior to offering the treatment and so should not be included in the decision-making process that determines whether the treatment is appropriate. This challenges the positions of Speck et al. (2016) and Djulbegovic et al. (1999), who hold that future regret should form an essential part of medical decision-making.

At this point, one may worry that the transformative nature of a treatment is a threat to a patient's capacity for autonomous choice. Can one make an autonomous decision to undergo a treatment that changes the kind of life that one leads and, perhaps, wants to lead? Does an inability to know what one's post-treatment self will be like mean that one cannot make an autonomous pre-treatment choice? I do not believe so. Let us assume that autonomy involves the ability to lead a life, which consists in acting in ways that are consistent with one's deeplyheld values, preferences and plans. When choosing to undergo a PTT, one should be sure that the treatment is consistent with who one is now. This will include preferences about who one wants to be and the life that one wants to have. For example, when requesting GCT, one should be confident that transitioning is consistent with the future life one envisages. It may be that the process of transitioning changes one's identity in a way that means that one does not want to stay as one's new sex/gender; one comes to want to lead a life that is different to the life one envisaged when deciding to transition. One will not know if this is the case until one has transitioned. However, if this occurs, then it would not mean that one's decision was, or is retrospectively rendered, non-autonomous. Rather, it shows there is a limit to what we can know and control when it comes to who we are and how we are changed by our decisions. It is important that this is acknowledged in medical decision-making.

\section{Does Post-treatment Regret Signify a Mistake?}

The above discussion has important implications for how regret is understood in medical decision-making. As was noted, some clinical researchers take patient-regret to reveal a mistake or flaw in the decision-making process through which treatment is identified as appropriate (Djordjevic et al. 2016; Olsson and Möller 2006). This implies that by improving the decision-making process, we can reduce post-treatment regret. This is partly right. For example, during the decision-making process we can try to ensure that the patient is sufficiently informed about what the treatment involves and its possible effects. A patient choosing a treatment without knowing about its effects can lead to regret, as sometimes occurs when women do not realise that sterilisation is permanent (Zite and Borrero 2011). ${ }^{18}$ However, there are occasions when patient-regret does not reveal a flaw or mistake in the decision-making process and could not have been eliminated by improving it.

These occasions occur when the patient's regret could not have been foreseen from the patient's or doctor's deliberative perspective at the time the decision was made. This is the case with personally transformative treatments, for it could not have been known how the patient would feel about the treatment until they went through it. Someone may have very good reasons for requesting GCT, based upon their feelings, embodied experiences and life-plans.

${ }^{18}$ Post-GCT regrets may also be linked to unrealistic expectations for, or unawareness of, what surgical results will be like (Davy 2011). 
However, their experience of transitioning and its effect upon their self changes these feelings and plans. They now do not want to live as their previously desired sex/gender. Because they could not have known beforehand what it would be like to experience first-personally the effects of transitioning (i.e. what it is like for them to transition), then the decision-making process could not have included this information. The decision to transition - which includes the clinician's decision to agree to the request for GCT - was based on the available information and was justified by it. ${ }^{19}$ In such scenarios, the future regret does not show that the decision-making process was flawed. ${ }^{20}$ We may hold instead that it is the patient's regret that is mistaken. The patient ought not regret their decision, precisely because it was justified at the time it was made.

To support this claim, we can distinguish two possible objects or targets of regret: decisions and outcomes. One may regret making a rash or otherwise poor decision and one may regret the effects of that decision. Typically, these will go together: I regret deciding to walk to the office today, despite hearing the weather forecast, because I am now soaked to the bone. The unpleasant outcome highlights the flaws in my decisionmaking. However, I might regret my decision-making despite the outcome: I regret thinking that I could jump the distance between two roofs because I fell onto the ground from a great height (I really ought to have known I would not make it - I only did it because I was urged on by friends). However, unbeknownst to me, there is a conveniently placed mattress, which cushions my fall. Thus, I do not regret the outcome - no bones were broken - even if I reproach myself for being so foolish. Finally, I may regret an outcome whilst not regretting the decision: I was right to book my holiday for the middle of July, when it is most likely to be warm and sunny, even though it happened to rain for the entire week. Despite how things panned out I do not reproach myself - I could not have predicted or controlled the weather, especially when booking my holiday six months earlier.

I suggest that our attitude toward patient-regret should, on certain occasions, be like the final example. We may wish that the outcome was different, but this does not provide sufficient warrant to regret the decision, if the decision was justified at the time it was made. Furthermore, when a treatment is personally transformative, and hence how I will feel about the outcome cannot be known prior deciding to undergo the treatment (because I cannot know how I will feel about the changes I undergo), then I cannot use it as a guide for assessing the soundness of my decision-making. My regret about the outcome should not transfer to regret about the decision itself. Importantly, because outcome-regret does not necessarily track decision-regret, I cannot always prevent outcome-regret by ensuring there is no decision-regret, and vice-versa. This implies that Olsson and Möller (2006) and Djordjevic et al. (2016), who hold that outcome-regret can be prevented by ensuring better decision-making, are mistaken. Patient-regret does not always signify a mistake or flaw in the decision-making process and improving it does not guarantee that the patient will be free from regret.

\footnotetext{
${ }^{19}$ This argument rests upon the assumption that the justification for a decision is fixed at the time it was made. For the claim that justification can be retrospective, see Williams (1981).

${ }^{20}$ The same argument applies to patient-regret about non-transformative treatments when the patient has been changed by other events or experiences in their life that leave them regretting their decision to undergo the treatment, and these events or experiences could not have been foreseen during the decision-making process.
} 


\section{Preventing All Regret}

In response to these claims, one may argue the following. Although we cannot determine beforehand who will or will not regret undergoing a PTT, we know that some people do experience post-treatment regret. ${ }^{21}$ Given that regret is unpleasant, we should try to prevent it. We can do this by withholding all PTTs (and only allowing non-PTTs when we are sure that the patient will not regret the treatment). Several points can be offered in response to this. First, we can invoke the argument above that respect for patient autonomy can outweigh the desire to prevent patient-regret. Second, it overlooks the fact that people also regret things they have not done. Thus, they can regret that they did not change sex/gender, become sterilised, undergo IVF or have plastic surgery. Withholding a treatment is not guaranteed to prevent regret. Third, research suggests that rates of regret for treatments such as SRS and VS are low (see footnote 20). To withhold a treatment because it can result in painful regrets for a minority of patients would be to throw the baby out with the bathwater.

Finally, it is important to consider the negative consequences of withholding treatment. Many trans individuals report the experience of gender dysphoria to be very distressing and insist that GCT helped to alleviate this distress (Davy 2011; Whittle et al. 2008). Thus, withholding it can result in a much lower level of well-being than if it is offered. Furthermore, many women who are denied sterilisation 'remain deeply, desperately worried about unwanted pregnancy' (Campbell 1999, 58). In addition, the denial of a sterilisation request can be experienced as a significant affront to one's autonomy and dignity, as well as unjustifiably paternalistic. This is especially the case given the importance that bodily autonomy has for a person's sense of self-control and dignity (particularly for women, given the lack of control that they have had historically over their bodies). Finally, if sterilisation is considered lifesaving - either because some women have medical conditions that would place their own lives and/or the lives of their foetus at risk, or because pregnancy and childbirth are inherently dangerous for women - then this would outweigh concerns about regret. Consequently, withholding a treatment owing to concerns about patient-regret may well be more harmful to the patient than if the treatment is offered. This is relevant given that concerns about patientregret are likely justified by appealing to patient well-being.

A clinician might respond to these points by appealing to the principles of non-maleficence and the difference between doing and allowing. She may say that she should not offer a treatment to a patient that results in regret, because this will be to harm the patient. This is relevantly different to the patient being harmed by not receiving a treatment, as the clinician has not caused it to occur. However, this argument relies on there being a tenable, morallyrelevant distinction between harm resulting from action and harm resulting from inaction, with the latter being preferable to the former. This assumption has been challenged (Singer 2011; Unger 1996). Relatedly, one may also hold that withholding treatment is still a choice that the clinician makes. Alternatively, if the patient is aware of the possibility of regret and still requests the treatment, then the clinician need not be identified as responsible for the harm of regret. As Brockwell (2015) asks in response to doctors' fears that she will regret being

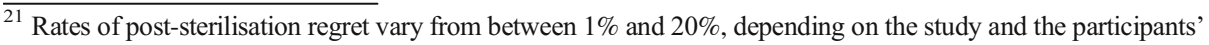
profile, e.g. age and number of offspring (Becner et al. 2015; Curtis et al. 2006; Hillis et al. 1999). Rates of postGCT regret are reported to be between 1\% and 5\% (Landén et al. 1998; Lawrence 2003; Smith et al. 2005). However, the data should be treated cautiously owing to sample sizes, populations studied (trans men are often excluded from research), the number of studies and how regret is conceptualised and measured within them. As noted above, people also regret undergoing IVF and having children.
} 
sterilised, 'how could I hold someone else responsible for my choice?'. ${ }^{22}$ Finally, the harm resulting from inaction may be far greater than harm that may result from action (even if it cannot be directly imputed to the clinician). This, I suggested, is likely to be the case with both GCT and VS.

\section{Conclusion}

Patient-regret is sometimes viewed by medical researchers and practitioners as (a) something to be avoided, and hence a strong reason against treatments that the patient may regret undergoing; and (b) a problem that indicates flaws or mistakes with the decision-making process through which a treatment is identified as appropriate. I have challenged both these beliefs. There are times when respect for patient autonomy should outweigh the clinician's desire to prevent the patient-regret. In addition, treatments that are personally transformative pose a problem for considering the possibility of regret as a reason against these treatments. Owing to the transformative nature of the treatment, the patient cannot know what it will be like to undergo the treatment and to experience its effects until they do so; they cannot know how they will later feel about undergoing the treatment because their identity will be altered by the treatment itself. This means that neither the patient nor their doctor can know whether the treatment will give rise to regret. In deciding whether to offer a PTT, the focus should be exclusively on the reasons that the patient has for requesting the treatment at the time of asking, rather than also considering what their post-identity will be like. This argument also suggests that post-treatment regret does not necessarily indicate a problem or a mistake / flaw in the decision-making process. A patient may come to regret undergoing some treatment, but this does not show that the treatment should not have been offered. Consequently, I have sought to show that regret should play a less prominent and negative role in medical decisionmaking than is currently the case. Hopefully, this will lead to more patients receiving treatment that they are justified in requesting but are currently denied owing to misplaced concerns about future regrets.

Acknowledgements This work was supported by the Irish Research Council [grant number GOIPD/2015/608]. I am extremely grateful to the journal's anonymous reviewers for their comments, which have improved the paper greatly.

Open Access This article is distributed under the terms of the Creative Commons Attribution 4.0 International License (http://creativecommons.org/licenses/by/4.0/), which permits unrestricted use, distribution, and reproduction in any medium, provided you give appropriate credit to the original author(s) and the source, provide a link to the Creative Commons license, and indicate if changes were made.

\section{References}

Bagnoli C (2000) Value in the guise of regret. Philos Explor 3:169-187

\footnotetext{
$\overline{{ }^{22} \text { Clinicians' worries about being }}$ responsible for a patient's regret, and related concerns about misdiagnosis, may be explained by / exacerbated in societies where accusations of malpractice and significant financial compensation claims are common. On her experience of denied sterilisation requests, Brockwell (2015) writes that, 'More than once, they've [doctors] expressed concern that I'll change my mind later and blame or even sue them'.
} 
Batty D (2004) Sex changes are not effective, say researchers. Guardian Newspaper. https:/www.theguardian. com/society/2004/jul/30/health.mentalhealth. Accessed 14 Oct 2017

BBC (2013) I wish IVF had never been invented. BBC News Magazine. http://beta.bbc.co.uk/news/magazine24725655. Accessed 14 Oct 2017

Beauchamp TL, Childress JF (2013) Principles of biomedical ethics, 7th edn. Oxford University Press, Oxford

Becner A, Turkanović AB, But I (2015) Regret following female sterilization in Slovenia. Int J Gynecol Obstet $130: 45-48$

Bittner R (1992) Is it reasonable to regret things one did? J Philos 89:262-273

Bourgeois-Gironde S (2010) Regret and the rationality of choices. Philos Trans Royal Soc B: Biol Sci $365: 249-257$

Brockwell H (2015) Why can't I get sterilised in my 20s? Guardian Newspaper. https://www.theguardian. com/commentisfree/2015/jan/28/why-wont-nhs-let-me-be-sterilised. Accessed 14 Oct 2017

Campbell A (1999) Childfree and sterilized: women's decisions and medical responses. Cassell, London

NHS Choices (2016) Gender dsyphoria - Treatment. http://www.nhs.uk/Conditions/Genderdysphoria/Pages/Treatment.aspx. Accessed 14 Oct 2017

Christie DRH, Sharpley CF, Bitsika V (2015) Why do patients regret their prostate cancer treatment? PsychoOncology 24:1002-1011

Christman J (ed) (1989) The inner citadel: essays on individual autonomy. Oxford University Press, Oxford

Connell C (2013) I wasted $£ 30,000$ trying to have a baby I didn’t want. The Guardian Newspaper. https://www. theguardian.com/lifeandstyle/2013/nov/16/30000-ivf-for-baby-didnt-want. Accessed 14 Oct 2017

Curtis KM, Mohllajee AP, Peterson HB (2006) Regret following female sterilization at a young age: a systematic review. Contraception 73:205-210

Daniluk JC (2001) "If we had to do it over again...": couples' reflections on their experiences of fertility treatments. Fam J 9:122-133

Davy Z (2011) Recognizing Transsexuals: personal, political and medicolegal embodiment. Routledge, London

Denbow JM (2015) Governed through choice: Autonomy, technology and the politics of reproduction. New York University Press, New York

Djordjevic ML, Bizic MR, Duisin D et al (2016) Reversal surgery in regretful male-to-female transsexuals after sex reassignment surgery. J Sex Med 13:1000-1007

Djulbegovic B, Hozo I, Schwartz A, McMasters KM (1999) Acceptable regret in medical decision making. Med Hypotheses 53:253-259

Donath O (2015) Regretting motherhood: a sociopolitical analysis. Signs 40:343-367

Duke S (2014) The transgender con? Many "transgender" people regret switch. The New American. https:/www.thenewamerican.com/culture/item/19507-the-transgender-con-many-transgender-people-regretswitch. Accessed 14 Oct 2017

Epstein RM, Street RL (2011) The values and value of patient-centered care. Anal Fam Med 9:100-103

Fausto-Sterling A (2000) Sexing the body. Basic Books, New York

Fergusson DM, Horwood LJ, Boden JM (2009) Reactions to abortion and subsequent mental health. Br J Psychiatry 195:420

Fernandes-Taylor S, Bloom JR (2010) Post-treatment regret among young breast cancer survivors. PsychoOncology 20:506-516

Flores AR, Herman JL, Gates GJ, Brown TNT (2016) How many adults identify as transgender in the United States? The Williams Institute. http:/williamsinstitute.law.ucla.edu/wp-content/uploads/How-Many-AdultsIdentify-as-Transgender-in-the-United-States.pdf?_ga=1.193854126.2012623534.1465157912. Accessed 14 Oct 2017

Gillespie R (2000) When no means no: disbelief, disregard and deviance as discourses of voluntary childlessness. Women's Stud Int Forum 23:223-234

Gilovich T, Medvec VH (1995) The experience of regret: what, when, and why. Psychol Rev 102:379-395

Glannon W (2009) Stimulating Brains, Altering Minds. J Med Ethics 35:289-292

Haas AP, Rodgers PL, Herman JL (2014) Suicide attempts among transgender and non-conforming adults. The Williams Institute. http://williamsinstitute.law.ucla.edu/wp-content/uploads/AFSP-Williams-Suicide-ReportFinal.pdf. Accessed 27 Oct 2017

Hillis SD, Marchbanks PA, Tylor LR, Peterson HD (1999) Poststerilization regret: findings from the United States Collaborative Review of Sterilization. Obstet Gynecol 93:889-895

Janis IL, Mann L (1977) Anticipatory regret. In: Janis IL, Mann L (eds) Decision making: a psychology analysis of conflict, choice, and commitment. Free Press, New York, pp 219-242

Jeffreys S (2008) They know it when they see it: the UK Gender Recognition Act 2004. Brit J Polit Int Stud 10: 328-345

Jeffreys S (2014) Gender hurts: a feminist analysis of transgenderism. Routledge, London

Jokisaari M (2003) Regret appraisals, age, and subjective well-being. J Res Pers 37:487-503 
Landén M, Wålinder J, Hambert G, Lundström B (1998) Factors predictive of regret in sex reassignment. Acta Psychiactr Scand 97:284-289

Landman J (1993) Regret: the persistence of the possible. Oxford University Press, Oxford

Lawrence AA (2003) Factors associated with satisfaction or regret following male-to-female sex reassignment surgery. J Sex Behav 32:299-315

Lawrence R, Rasinski K, Yoon J, Curlin F (2011) Factors influencing physicians' advice about female sterilization in USA: a national survey. Hum Reprod 26:106-111

Mackenzie C, Stoljar N (eds) (2000) Relational autonomy: feminist perspectives on autonomy, agency, and the social self. Oxford University Press, Oxford

Maguire GQ Jr, McGee EM (1999) Implantable brain chips? Time for debate. Hast Cent Rep 29:7-13

Major B (2000) The psychological effects of first trimester abortion. Arch Gen Psychiatry 57:777-784

Marsh S (2017) "It's the breaking of a taboo": the parents who regret having children. Guardian Newspaper. https://www.theguardian.com/lifeandstyle/2017/feb/11/breaking-taboo-parents-who-regret-having-children. Accessed 14 Oct 2017

Matthews DJH (2011) Deep brain stimulation, personal identity and policy. Int Rev Psychiatry 23:486-492

McKinnon R (2015) Trans*formative experiences. Res Philos 92:419-440

Meier SC, Labuski CM (2013) The demographics of the transgender population. In: Baumle AK (ed) International handbook on the demography of sexuality. Springer, Dordrecht, pp 289-327

Mertes H (2016) The role of anticipated decision regret and the patient's best interest in sterilisation and medically assisted reproduction. J Med Ethics 1-5

Nealy EC (2017) Transgender children and youth. W. W, Norton

Olsson S-E, Möller A (2006) Regret after sex reassignment surgery in a male-to-female transsexual: a long-term follow up. Arch Sex Behav 35:501-506

Paul LA (2014) Transformative experience. Oxford University Press, Oxford

Reed B, Rhodes S, Schofield P, Wylie K (2011) Gender variance in the UK: prevalence, incidence, growth and geographic distribution - update 2011. Gender Identity Research and Education Society. http://www.gires. org.uk/wp-content/uploads/2014/10/Prevalence2011.pdf . Accessed 14 Oct 2017

Richie C (2013) Voluntary sterilization for childfree women: understanding patient profiles, evaluating accessibility, examining legislation. Hast Cent Rep 43:36-44

Rorty AO (1980) Agent regret. In: Rorty AO (ed) Explaining emotions. University of California Press, Berkeley pp 489-506

Rubin H (2003) Self-made men: Identity and embodiment amongst transsexual men. Vanderbilt University Press, Nashville

Singer P (2011) Practical ethics, 3rd edn. Cambridge University Press, Cambridge

Smith YSL, van Goozen SHM, Cohen-Kettenis PT (2001) Adolescents with gender identity disorder who were accepted or rejected for sex reassignment surgery: a prospective follow-up study. J Am Acad Child Adolesc Psychiatry 40:472-481

Smith YSL, van Goozen SHM, Kuiper AJ, Cohen-Kettenis PT (2005) Sex reassignment: outcomes and predictors of treatment for adolescent and adult transsexuals. Psychol Med 35:88-99

Speck RM, Neuman MD, Resnick KS et al (2016) Anticipated regret in shared decision-making: a randomized experimental study. Pers Med 5:1-7

Svenaeus F (2012) Organ transplantation and personal identity: how does loss and change of organs affect the self? J Med Philos 37:139-158

Swindell JS (2007) Facial allograft transplantation, personal identity and subjectivity. J Med Ethics 33:449-453

Unger P (1996) Living high and letting die. Oxford University Press, Oxford

Wallace RJ (2013) The view from here: on affirmation, attachment, and the limits of regret. Oxford University Press, Oxford

Whittle S, Turner L, Combs R, Rhodes S (2008) Transgender eurostudy: legal survey and focus on the transgender experience of health care. ILGA Europe and Transgender Europe

Williams BAO (1981) Moral luck. In: Williams BAO (ed) Moral luck: philosophical papers 1973-1980. Cambridge University Press, Cambridge, pp 20-39

Zeelenberg M (1999) Anticipated regret, expected feedback and behavioral decision making. J Behav Decis Mak 12:93-106

Zeelenberg M, Pieters R (2007) A theory of regret regulation 1.0. J Consum Psychol 17:3-18

Zeelenberg M, Beattie J, Van der Pligt J, De Vries N (1996) Consequences of regret aversion: effects of expected feedback on risky decision making. Organ Behav Hum Decis Process 65:1480-1158

Zeelenberg M, van Dijk WW, Manstead ASR, vanr de Pligt J (2000) On bad decisions and disconfirmed expectancies: the psychology of regret and disappointment. Cognit Emot 14:521-541

Zite N, Borrero S (2011) Female sterilisation in the United States. Eur J Contracept Reprod Health Care 15:336-340 